\title{
Identification and Controlled of Short Duration Voltage Disturbance by Using RMS Algorithm of Distribution System
}

\author{
Miss. Anjali Nandkumar Jambhulkar ${ }^{1}$, Prof.R.M. Bhombe ${ }^{2}$, Prof. Yogesh Likhar ${ }^{3}$, Prof. Hitesh \\ Murkute $^{4}$ \\ ${ }^{1}$ PG Student, Department of Electrical Engineering (PEPS), Gurunanak institute of engineering and technology Nagpur, \\ Maharashtra India \\ ${ }^{2,3,4}$ Professor's E.E, Gurunanak institute of engineering and technology Nagpur, Maharashtra India
}

Received on: 07 May, $2021 \quad$ Revised on:06 June, $2021 \quad$ Published on:08 June, 2021

\begin{abstract}
Delivering good quality of power is the main agenda for distribution system to the loads. But maintain power quality is not so easy due to the load variations in the system. Sag and swell are the main factors that affect power quality. In this paper, multiple sag conditions and swell conditions were tested by producing the condition in different phases of the system. A simple algorithm called RMS algorithm was developed and tested for the said conditions. Sag and swell were generated on single phase and multiple phases for testing the algorithm. The algorithm and the results were obtained using Matlab. .DVR is installed between supply and load which will inject voltage and active power to the distribution system during balanced/unbalanced voltage sag and swell disturbances. The performance of DVR based of voltage sag, swell is going to be tested and Simulation results are going to be carried out by MATLAB with its Simu-link to analyze the proposed method.
\end{abstract}

Key Words: RMS (root mean square), DVR (dynamic voltage restorer), sag, swell

\section{1-INTRODUCTION}

$\mathbf{I}$ n electrical engineering, the Ferranti effect is an increase in voltage occurring at the receiving end of a long transmission line, above the voltage at the sending end. This occurs when the line is energized, but there is a very light load or the load is disconnected. The capacitive line charging current produces a voltage drop across the line inductance that is in-phase with the sending end voltages considering the line resistance as negligible. Therefore, both line inductance and capacitance are responsible for this phenomenon. In general practice we know, that for all electrical systems current flows from the region of higher potential to the region of lower potential, to compensate for the electrical potential difference that exists in the system. In all practical cases the sending end voltage is higher than the receiving end, so current flows from the source or the supply end to the load. But Sir S.Z. Ferranti, in the year 1890, came up with an astonishing theory about medium distance transmission line or long-distance transmission lines suggesting that in case of light loading or no-load operation of transmission system, the receiving end voltage often increases beyond the sending end voltage, leading to phenomena known as Ferranti effect in power system. Voltage sags caused by the short-circuit faults in transmission and distribution lines have become one of the most important power quality problems facing industrial customers and utilities. Power quality issues like transients, sags, swells and alternative to the curving wave shape of the availability voltage have an effect on the performance of those instrumentality items. The main objective of the paper is to generate and controlled sag and swell in different phases of the system and analyze them. A simple RMS algorithm was generated to analyze the condition of the system, whether the sag/swell exists in the system by using Matlab. Most of these faults that occur on power systems are not the balanced threephase faults, but the unbalanced faults. In the analysis of power system under fault conditions, it is necessary to make a distinction between the types of fault to ensure the best results possible in the analysis. In balanced voltage sag \& swell, voltage decreases and increase in all three phases simultaneously. In 


\section{International Journal of Innovations in Engineering and Science, www.ijies.net}

unbalanced voltage sag \& swell voltage decrease and increases in only one phase or two phases at a time.

\subsection{Overview}

Power quality determines the quality of electric power to load devices. Maintaining frequency, voltage and power factor within nominal values makes load to function properly without stress on the devices. This maintenance of power quality also reduces the losses in the system increasing the life of the equipment connected. Voltage sags and swells are the common reasons for interruption in production plants and for end instrumentality malfunctions generally, specifically, in economical identification will cause disruption and vital prices attributable to loss of production. One solution to the present downside is to create the instrumentality itself additional tolerant to sags, either by intelligent management or by storing energy within the instrumentality. Voltage sags caused by the short-circuit faults in transmission and distribution lines have become one of the most important power quality problems facing industrial customers and utilities. Power quality issues like transients, sags, swells and alternative to the curving wave shape of the availability voltage have an effect on the performance of those instrumentality items. The main objective of the paper is to generate and controlled sag and swell in different phases of the system and analyze them. A simple RMS algorithm was generated to analyze the condition of the system, whether the sag/swell exists in the system by using Matlab.

\section{II- PROBLEM DEFINATION AND OBJECTIVES}

Power quality is very important issue recently due to the impact on electricity suppliers, equipment manufacture and customers. Power quality is described as the variation of voltage, current and frequency in a power system. It refers to a wide variety of electromagnetic phenomena that characterize the voltage and current at a given time and at a given location in the power system. Nowadays, there are so many industries using high technology for manufacturing and process unit. This technology requires high quality and high reliability of power supply. The industries like semiconductor, computer, and the equipments of manufacturing unit are very sensitive to the changes of quality in power supply. Power Quality problems encompass a wide range of disturbances such as voltage sags/swells, flicker, harmonics distortion, impulse transient, and interruptions. Voltage sags/swells can occurs more frequently than other Power quality phenomenon. These sags/swells are the most important power quality problems in the power distribution system.

The main objective of the paper is to generate and controlled sag and swell in different phases of the system and analyze them. A simple RMS algorithm was generated to analyze the condition of the system, whether the sag/swell exists in the system. This method will be tested using MATLAB simulation.

\section{III- PROJECT IMPLEMENTATION}

Power system disturbances can occur as general phenomenon and these disturbances are of two types-long term duration and short duration disturbances. Long duration disturbances are the disturbances that persist for the duration more than 1 minute. If the duration of the fault is less than 1 minute, the fault is termed as short duration fault. Long duration voltage raise is called over voltage and short duration voltage raise is called swell. Similarly, long duration voltage drop is termed as under-voltage and short duration voltage drop is termed as sag. Sag is a general phenomenon that occurs due to energizing heavy loads or starting of large motors. Voltage sag might cause poor efficiency and decreases the life time of the device connected. Swell might cause the device to be damaged. This causes the power system to poor power quality.

A simple algorithm called RMS algorithm was developed to detect the sag/swell in the system. Sag or swell can cause unusual operation of the system. Thus, the sag and swell should be avoided. But in the power system due to load variations these sag and swell cannot be avoided and these are very general phenomenon as per the power system is concerned. But measures should be taken to reduce the sag/swell. To take any action the first step needed is to identify the parameter. Here the identification of sag/swell is much important to take necessary action against to reduce the quantity of sag/swell and bring the voltage level to nominal value. Also, the identification is required in how many phases sag/swell are present in the system. So, a simple RMS algorithm was developed only for identification of sag swell for different cases.

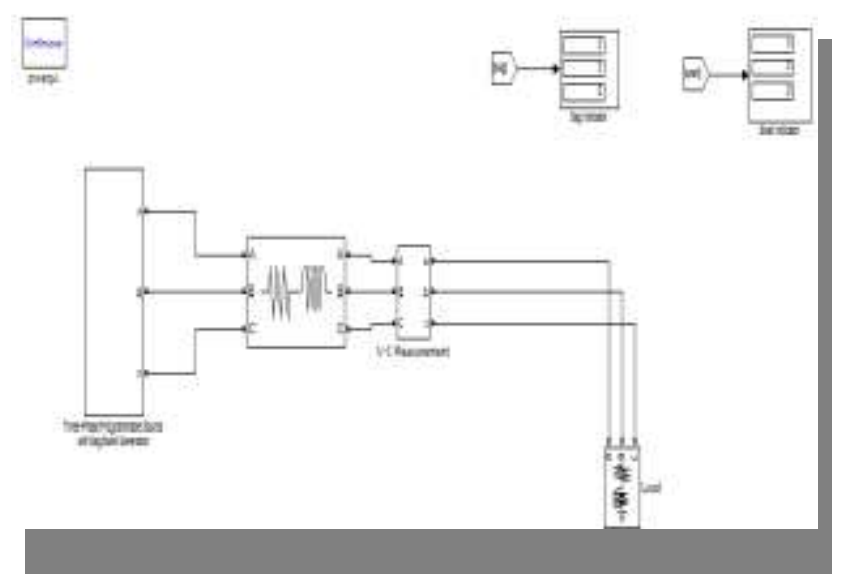

Fig 3 simulation Model of Sag/Swell Identification without DVR 


\section{International Journal of Innovations in Engineering and Science, www.ijies.net}

Table 3- show different cases of sag and swell in three phase system

\begin{tabular}{|c|c|c|c|c|c|c|c|}
\hline CASES & & $\overline{\mathrm{TAC}}$ & & & $\mathrm{ES}$ & & RESLITS \\
\hline Cas: 1 & 0 & 0 & 0 & 0 & 0 & 0 & No sag and no sutl \\
\hline Cas:? & 1 & 0 & 0 & 0 & $\theta$ & $\theta$ & Saguphasel \\
\hline Casi 3 & 1 & 0 & 0 & 0 & 1 & 8 & Sagin phase $1 \&$ snell in phase? \\
\hline Case & 1 & 0 & 0 & 0 & 1 & I & Sagningase 1 snel in $2 \& 3$ phas: \\
\hline Cant5 & 1 & I & 0 & 0 & 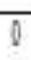 & 0 & Sagniphase $1 \mathrm{k} 2$ \\
\hline Case 6 & 1 & ! & 0 & 0 & 0 & I & Saginphase $1 \&$ Is stlin phasse \\
\hline Cax? & 1 & t & 0 & 0 & 1 & I & Sagmphas: $1 k 2$ smel in phas: $2 k\}$ \\
\hline Can: 8 & 1 & 1 & 0 & 1 & 1 & 1 & Sagin $1 \& 2$ phase snel in phase $12 \mathrm{k}$ iphase \\
\hline
\end{tabular}

\section{1 simulation model with DVR}

The performance of the DVR is demonstrated for different supply voltage disturbances such as balanced and unbalanced sag and swells at terminal voltages. The DVR is modeled and simulated using the MATLAB and its Simulink. In cases we only identify the weather sag in the system or swell in the system or both sag \& swell in the system. By using the compensating device (dynamic voltage restorer) we can controlled the sag and swell in the system. Above model consist of DVR which can controlled sag and swell in the system .

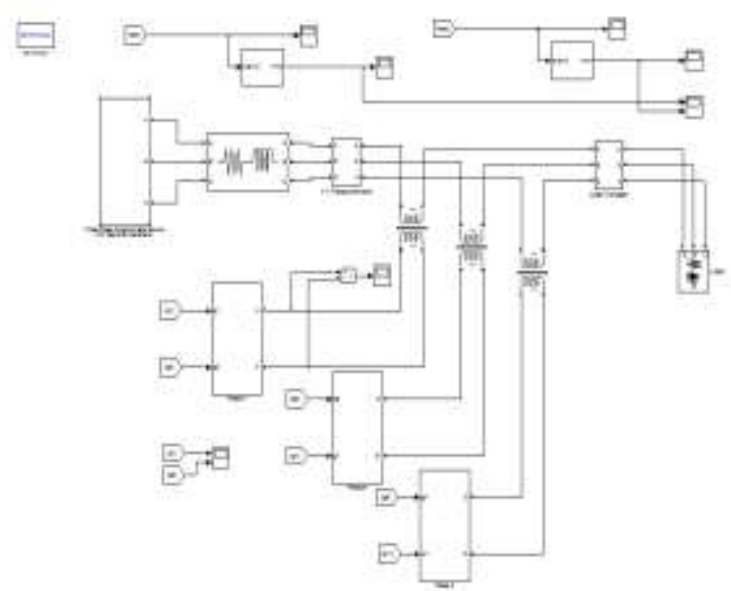

Fig 4.1- Matlab/Simulink model with DVR for Sag/Swell Condition.

\section{IV- SIMULATION RESULT}

Case: 1 When No Sag and No Swell Present in The System
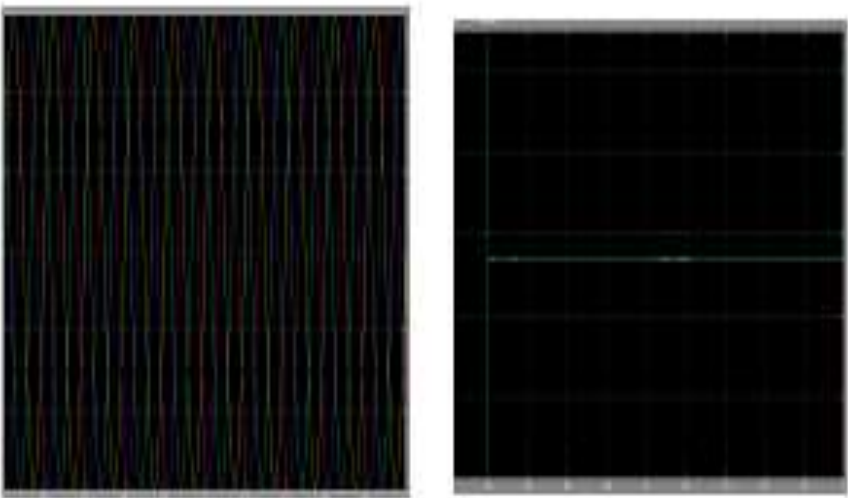

Figure 4.1.1 Result showing no sag/swell present in the system

Case 2: When Only Sag Exists In 1 Phase of the System
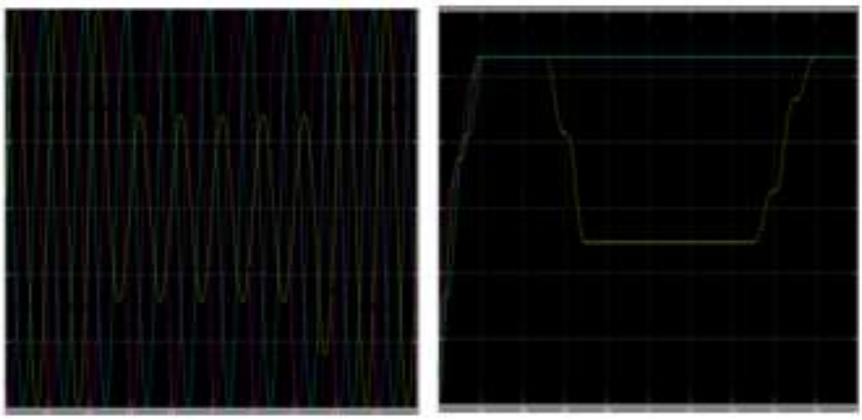

Figure 4.1.2 Result showing sag present in 1 phase of the system

Case 3: When Sag In Phase 1 and Swell in Phase 2 Present In the System
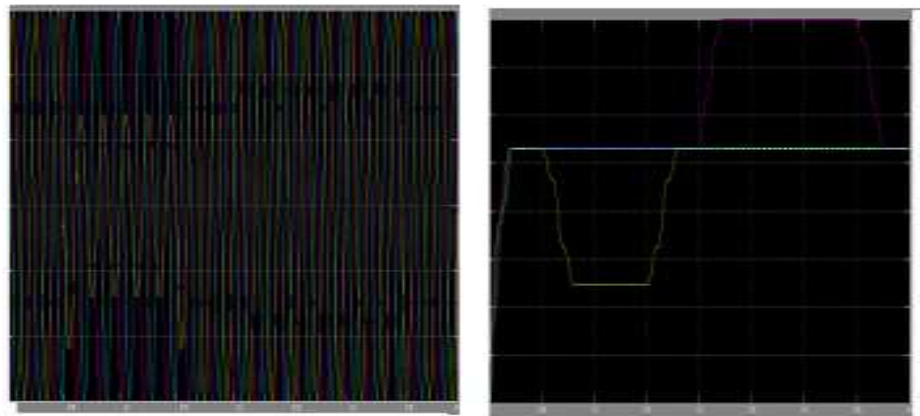

Figure 4.1.3 Result showing sag in phase 1 and swell in phase 2 present in the system 


\section{International Journal of Innovations in Engineering and Science, www.ijies.net}

Case 4: When sag In Phase 1 and Swell in Phase 2 and 3
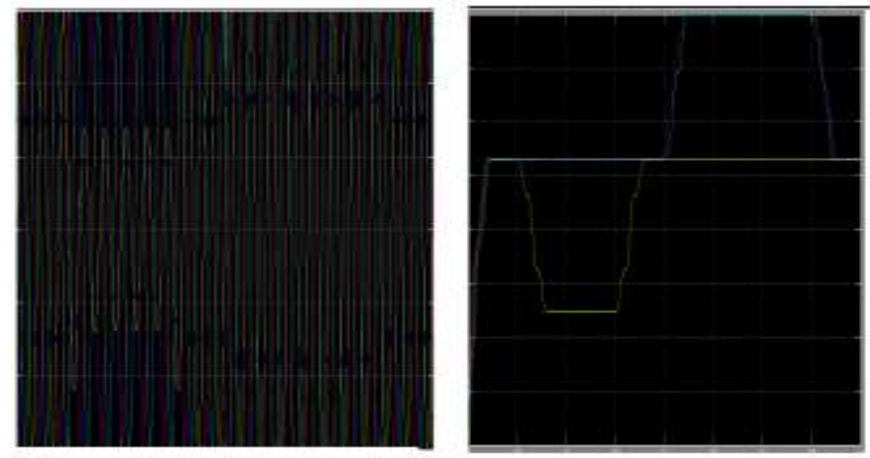

Figure 4.1.4-Result showing sag in phase 1 and swell in phase 2 present in the system

Case 5: When Sag In 2 Phases and No Swell in Any Phase
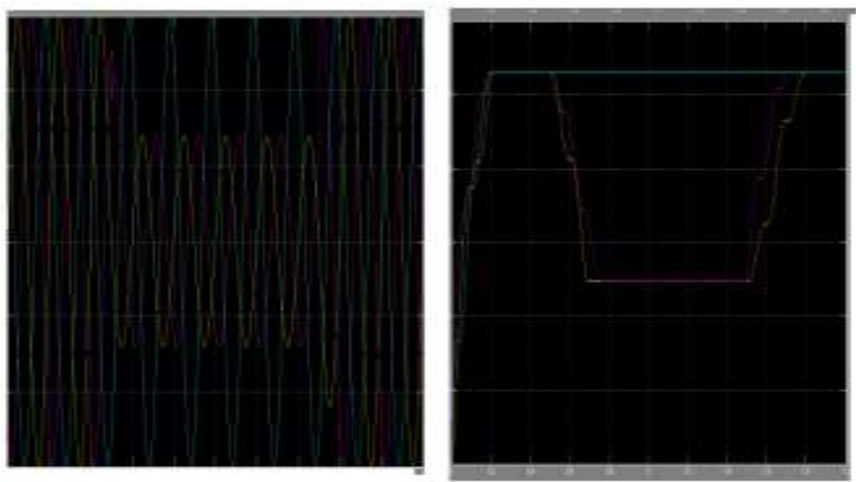

Figure 4.1.5 Result showing sag in 2 phase and no swell in any phase

Case 6: When Sag In 1 and 2 Phase and Swell in Phase 3
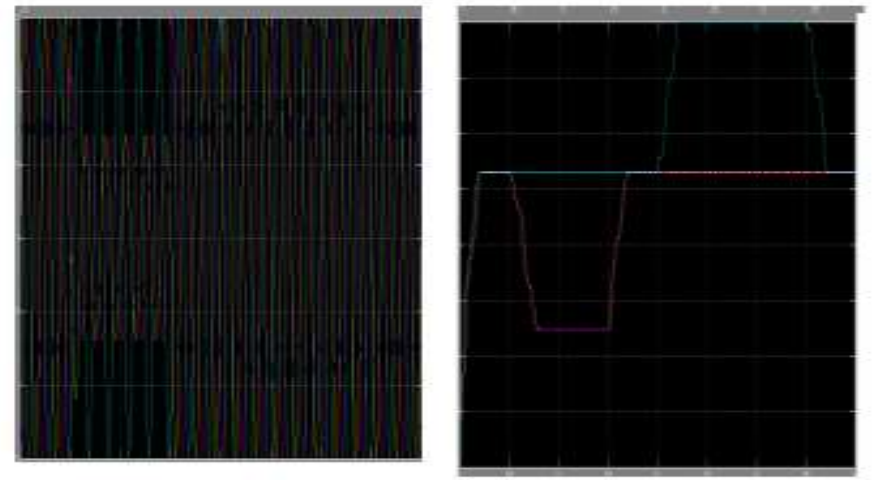

Figure 4.1.6 Result showing sag in 1 and 2 phase and swell in phase
Case 7: when sag in phase 12 and swell in phase 2 and 3
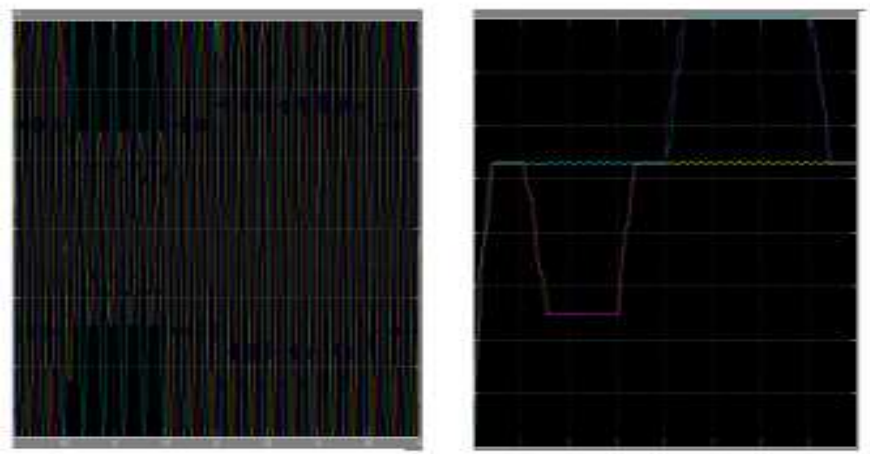

Figure 4.1.7 Result showing sag in phase 12 and swell in phase 2 and 3

Case 8: When Sag In 12 Phase and Swell in Phase 123
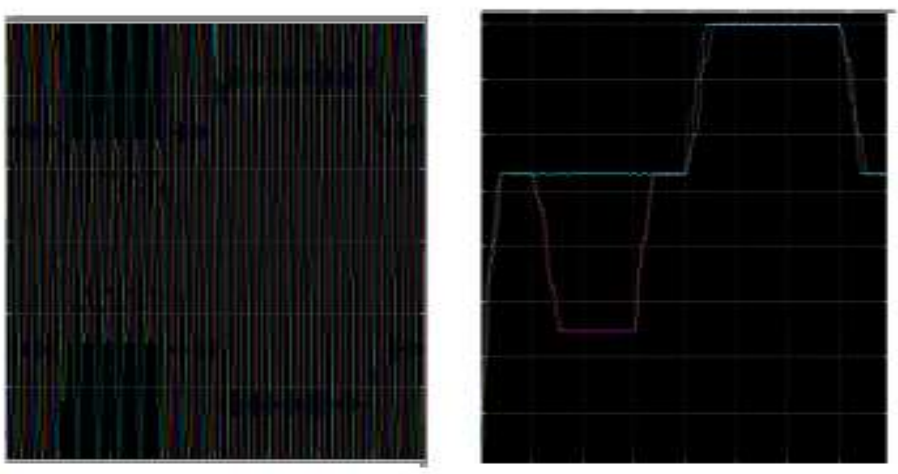

Figure 4.1.8 Result showing sag in 12 phase and swell in phase 12

\subsection{Matlab Results When Compensating Device Used in 3 Phase System}

In above case studies we are only identify that, when sag and swell occur in the system, but with the help of compensator device (DVR) we not only identify but also controlled sag and swell

\subsubsection{Result of 3 Phase System without Compensating Device} (DVR)

In this result sag in three phases and swell in three phases 


\section{International Journal of Innovations in Engineering and Science, www.ijies.net}
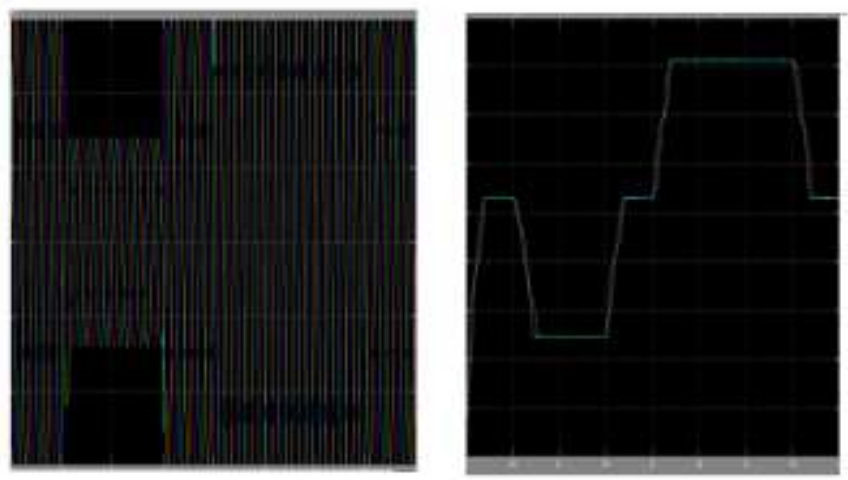

Figure 4.2.1 Waveform of 3 phase system of source when sag in 3 phases and swell in 3 phases

4.2.2- Result of 3 phase system when sag and swell in 3 phase is removed by using compensating device DVR
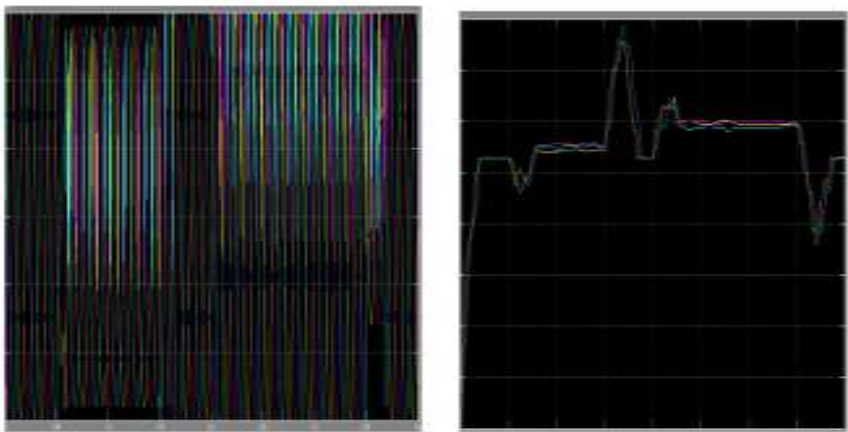

Figure 4.2.2 Waveform of 3 phase system of source when sag in 3 phases and swell in 3 phases is removed

4.2.3 Results with and without compensating device Below result show without compensating device sag in three phases and swell in three phase when disturbance occur such as power system harmonic, power frequency disturbance, power factor etc. .Second waveform shows sag and swell in the system is removing by using DVR

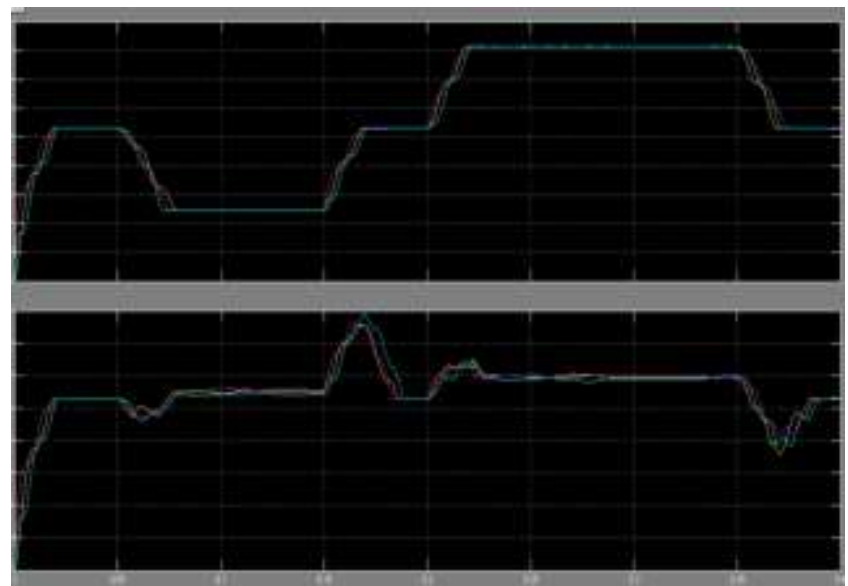

Figure 4.2.3 Wave form of with and without compensating device

\section{V-CONCLUSION}

Sag/swell detection algorithm has been proposed and compared and implemented by using Matlab algorithms. The simulation study of algorithm has been presented in this paper for extracting voltage component of source voltage under sag/swell conditions. The function of in Matlab is a powerful tool for doing that even with noisy signals. The identification process is very accurate. The simulation results shows that sag/swell have been identified and controlled by using DVR (dynamic voltage restorer). This algorithm explained is very simple and can effectively detect the presence of sag/swell in the system. Different cases have been considered for the production of sag/swell and the results were shown.

\section{REFERENCES}

[1] S.Sankara Prasad "transient stability International Journal of Electrical Engineering \& Technology(IJEET) Volume 7, Issue 3, May-June, 2016

[2] K. V. Satpute, 2 P. S. Vaidya M-tech IPS Electrical Department, G. H. Raisoni college of engineering, Nagpur, Maharashtra, India. Asst. Professor in Electrical Department, G. H. Raisoni college of engineering, Nagpur, Maharashtra, India IJCAT - International Journal of Computing and Technology Volume 1, Issue 1, February 2014

[3] R. Jayabarathi, M.R Sindhu, N. Devarajan, And T. N. P. Nambiar," Development of a Laboratory Model of Hybrid Static Var Compensator." 0-7803-9525-5/06/\$20.00@ 2006 IEEE.

[4] S. Torseng, Dr. Tech., "Shunt-Connected Reactors And Capacitors Controlled By Thyristors." IEE Proc, Vol. 128, Pt. C, No. 6, November 1981.

[5] M.Arunachalam R. Rajan Bahu Bhaskar Bose Dipak Dutta," Evaluation of Losses in Thyristors Valve for Svc Application." 07803-2795-0@2005

[6] Patricio Mendoza-Araya, Jaime Muñoz Castro, JaimeCotos Nolasco, and Rodrigo E. Palma-Behnke, "Lab-Scale Tcr-Based Svc System For Educational and Applications." IEEE Transactions on Power System Vol. 26, No. 1, February 2011.

[7] IEEE Industry Applications Magazine, "Before and During Voltage sags", available at, accessed o 25th of August 2008.

[8] E. Norbert, "Effects of voltage sags, swell and other disturbances on electrical equipment and their economic implications", 20th International Conference on Electricity Distribution, Prague, 8-11 June 2009.

[9] "IEEE Recommended Practice for Monitoring Electric Power Quality," IEEE Std. 1159-1995, June 1995.

[10] A. Sannino, J. Swensson, T. Larsson, "Power-Electronic Solutions to Power Quality Problems, "Electric Power Systems Research, 66:71-82, 200 